\title{
Association Between Umbilical Cord Coiling Index and Prenatal Outcomes
}

\author{
Forozan Milani $^{1}{ }^{\mathbb{D}}$, Seyedeh Hajar Sharami ${ }^{1}$, Ehsan Kazemnejad Lili ${ }^{2}$, Fatemeh Ebrahimi ${ }^{{ }^{\star}}{ }^{(\mathbb{D}}$, Seyedeh \\ Fatemeh Dalil Heirati ${ }^{1}$
}

\begin{abstract}
Objectives: This study aimed to measure the umbilical cord indices (UCIs) after birth and to determine its relationship with prenatal complications.

Materials and Methods: The present analytical cross-sectional study was conducted on all the pregnant women admitted to AlZahra hospital of Rasht. After birth, the umbilical cord was measured in terms of the appearance, number of vascular coils, and umbilical cord length. In addition, the umbilical cord vascular coils index was calculated. Further, maternal and neonatal variables were evaluated.

Results: The mean number of umbilical cord coils, umbilical cord length, and the umbilical cord coiling index for 397 umbilical cords were obtained as $16.02 \pm 4.48,51.6 \pm 12.0$ and $0.31 \pm 0.05 \mathrm{~cm}$, respectively. In evaluating the state of the coil, $9.8 \%$ were found as hypocoil while the remaining were either hypercoil (10.3\%) or normocoil (79.85\%). Furthermore, a significant difference was observed between the umbilical cord coiling index, as well as gestational hypertension and abnormal fetal heart rate $(\mathrm{HR})(P<0.05)$. In the final logistic regression model, the umbilical cord length was recognized as a predictor variable for neonatal complications. Moreover, in multiple analyses regarding the effects of umbilical cord coiling index on neonatal complications by controlling the interferences, variables such as maternal age and parity in addition to the coil length were considered as predictors of neonatal complications.

Conclusions: Generally, the abnormal umbilical cord coiling index was associated with pregnancy blood pressure (BP) and abnormal fetus HR. Therefore, diagnosing antenatal umbilical cord coiling index can be helpful in recognition of embryos at risk through a faster treatment process.

Keywords: Umbilical cord, Coiling index, Prenatal, Pregnancy outcomes
\end{abstract}

\section{Introduction}

The umbilical cord is a communicative bridge between the fetus and placenta, through which the fetus receives food, oxygen, and fluids essential for life from the placenta. The umbilical cord contains two arteries and one vein covered by Wharton's jelly, the external layer of which is surrounded by amnion fluid with a length of about 50$60 \mathrm{~cm}$ at the term time. Any damage or disruption in the cord could lead to perinatal complications. Many features of human umbilical cord have remained unknown (14). However, in recent years, interest has increased in examining the umbilical cord coils and its role.

On average, the umbilical cord has 11 loops or turns along its length between the fetus and placenta. The umbilical coil index (UCI) is measured by dividing the number of complete vascular coils by the cord length in $\mathrm{cm}$. The average is about $0.2 \pm 0.1$ of the full circle in $\mathrm{cm}(5)$, that is, one coil per $5 \mathrm{~cm}$. The UCI is considered hypocoil if it is below the 10th percentile. However, it is referred to as either hypercoil or normocoil in case it is above the 90th percentile or between 10 and 90 percentiles (6).
There is a strong association between UCI and adverse perinatal outcomes including intrauterine growth restriction (IUGR), stillbirth, low Apgar score, and the like which can suggest that the umbilical cord coils may have clinical relevance (5-10). It seems that increasing the ability of cord coiling can compensate for the adverse effect of external forces such as tension, pressure, stretching, or entanglement without disruption in the flexibility. Approximately 5\% of embryos are without vascular coiling $(6,11)$.

The possible mechanism for the relationship between abnormal umbilical cord coil and adverse clinical outcomes is unclear, but the hypothesis supports the issue that the correlation between fetal secondary hypoxia and increased vulnerability of the umbilical cord is due to pressure or entanglement (5). Various studies demonstrated that the hypercoil and hypocoil abnormal cord coiling indexes were associated with the adverse perinatal outcomes (8).

It seems that the embryos with no coiled or smooth cord are at an increased risk of perinatal adverse complications. The rate of stillbirth was noted about $8 \%-10 \%$ in cases 
of coiling absence. Similarly, a substantial increase was reported regarding the absence of cord coiling in the rate of intrauterine growth retardation, oligohydramnios, fetal abnormalities, decreased fetal heart rate (FHR) during labor, surgical interventions due to fetal distress, meconium-stained amniotic fluid, preterm deliveries, low Apgar score, low $\mathrm{pH}$ of umbilical artery, and the need for the neonatal intensive care unit (NICU) in newborns $(6,7)$. Interestingly, the high umbilical cord coiling is associated with increased fetal adverse complications as well. Although $30 \%$ of umbilical cords without coiling before 20 weeks of pregnancy have coiling later, an umbilical cord with sufficient coiling would not become no-coiled later $(4,6)$. Nonetheless, the definition of abnormal coiling is not fixed yet in the articles and its range for hypercoil and hypocoil is with an error or varies under the influence of gestational age (12).

Regarding the adverse effects observed in any type of coiling, the present study sought to measure the umbilical cord coiling index after birth. Additionally, its relationship with perinatal complications was investigated. Obviously, in case of a proven relationship, the complications can be prevented through an early ultrasound examination and a more accurate control at a high-risk pregnancy.

\section{Materials and Methods}

The population of the study included all the pregnant women hospitalized for natural singleton labor with a gestational age (based on last menstrual period [LMP] or ultrasound confirmation of the first quarter) of over 26 weeks with the cephalic presentation in Al-Zahra hospital of Rasht. The purposes of the study were explained to pregnant women and informed consent was obtained accordingly. The sampling was gradually conducted based on mothers' referral for labor using a non-probability approach. The exclusion criteria included women with smoking or drug addictions, preterm rupture of membrane (PROM), a temperature equal to or higher than $37.8^{\circ} \mathrm{C}$, multigestational pregnancy, any type of vaginal bleeding, placenta previa, the risk of placental abruption, cesarean section, and a history of abortion or stillbirth. A total of 397 mothers and infant umbilical cords were studied. After birth, the umbilical cord was examined in terms of its appearance by the researcher (an obstetrician as a collaborator of the project and a trained midwife). In addition, the number of vascular coils along the total length of the umbilical cord was counted. Further, the umbilical cord length was measured from the connection site to the placenta, to the clamped site of the baby, or to the baby belly ( $5 \mathrm{~cm}$ needs to be added). A vascular coil was considered as a full 360 degrees circle of the umbilical cord vessels. Then, the umbilical cord coils index was calculated dividing the number of vascular coils by the cord length in centimeters (12). The UCIs below the 10th percentile, greater than the 90th percentile, and between the 10th and 90th percentiles were considered hypocoil, hypercoil, and normocoil, respectively (12). Then, information regarding the following variables was recorded in the data collection forms:

1. Maternal variables such as age, parity, number of delivery, the risk of pregnancy-induced hypertension (pregnancy transient high blood pressure [BP], preeclampsia, and eclampsia, overt diabetes or gestational diabetes, oligohydramnios, and polyhydramnios);

2. Perinatal variables including abnormal fetal HR, excretion of meconium; and

3. Neonatal variables like birth weight (in grams), Apgar scores in the first and fifth minutes, fetal distress, a need to NICU, intrauterine growth retardation, and fetal anomalies.

\section{Statistical Analysis}

Data were analyzed by SPSS (Statistical Package for the Social Sciences) software, version 21. The mean and standard deviation (SD) were used to determine and describe the quantitative variables. Furthermore, nonparametric Mann-Whitney and Kruskal-Wallis tests were employed to compare these indicators based on the characteristics of the mother and underlying diseases or disorders. The correlation coefficient was applied to evaluate the correlation between quantitative variables and maternal age, parity, Apgar scores (at minutes 1 and 5), and birth weight. Moreover, logistic regression model by backward LR (logistic regression) method was used to determine the predictors of neonatal complications in both identical and non-identical models. The significance level of the tests was considered $P<0.05$.

\section{Results}

Totally, 397 pregnant women were investigated in terms of the relationship between umbilical cord coils index and the neonatal outcomes in deliveries conducted in Al-Zahra hospital from May 2015 to May 2016. Table 1 shows the participants' age distribution and the number of birth given. The mean (SD) of the number of umbilical cord coils in the studied samples was $16.02 \pm 4.48$ with

Table 1. Distribution of Age and Parity in the Sample Population

\begin{tabular}{lc}
\hline Variable & No. (\%) \\
\hline Maternal age $(\mathrm{y})$ & $73(18.4)$ \\
$>20$ & $111(28)$ \\
$21-25$ & $96(24.2)$ \\
$26-30$ & $70(17.6)$ \\
$31-35$ & $47(11.8)$ \\
$<35$ & \\
Parity & $251(63.2)$ \\
1 & $105(26.4)$ \\
2 & $31(7.8)$ \\
3 & $10(2.6)$ \\
\hline 4
\end{tabular}


a $95 \%$ confidence interval (15.57-14.46). In addition, the minimum and maximum numbers of umbilical cord coils were 5 and 28, respectively. Examining the umbilical cord length, the mean (SD) of the umbilical cord length was found to be $51.6 \pm 12.0$ with a $95 \%$ confidence interval (50.45-52.82). The minimum and maximum umbilical cord lengths were equal to 20 and $97 \mathrm{~cm}$, respectively. As regards the UCIs, the mean $(\mathrm{SD})$ was $0.31 \pm 0.05$ with a 95\% confidence interval (0.30-0.31) with UCI minimum and maximum of 0.07 and 0.45 , respectively.

The 10th and 90th percentiles were considered to determine the coil status. The range between the 10th and 90th percentiles was obtained $0.23-0.37$, which were accordingly divided into three groups. Further, evaluating the state of the coil, which is a benchmark of the number of coils to the coils length ratio, 9.8\% $(n=39)$ were regarded as hypocoil while $10.3 \%(\mathrm{n}=41)$ were hypercoil, and the remaining $79.85 \%(n=317)$ were normocoil.

Based on the result of the Fisher test (Table 2), a significant difference was found between the UCI and gestational hypertension $(P<0.05)$.

Comparing the umbilical cord coils index in terms of abnormal fetal HR, it was revealed that it had a significant difference with abnormal fetal heart rate $(P=0.03)$.

As shown in Table 3, comparing the UCI based on gestational age, birth weight, and Apgar scores at the first and fifth minutes, no relationship was found between the UCI and any of the variables according to the ANOVA test.

In a comparative evaluation of UCIs regarding neonatal complications (Table 4), the results indicated that the UCI was significantly based on none of the neonatal complications during hospitalization in neonatal intensive care, intrauterine growth retardation and excretion of meconium $(P>0.05)$. Meanwhile, no cases of the fetal anomaly were detected.

As regards the combination of three complications, namely, admission to the NICU, excretion of meconium, and retardation of intrauterine growth as one variable which is called neonatal complications, based on Table 5, the findings demonstrated that, in general, both groups of infants with and without neonatal complications had no significant difference in terms of UCI $(P=0.92)$.

As previously pointed out, the logistic regression model was used in the multi-analysis of UCI effects on neonatal complications, the results of which are 0.05 and 0.1 for entry and exit probability employing the backward approach. Furthermore, in the unadjusted model, that is, the final logistic regression model, the cord length, among others (i.e., UCI, cord length, and the number of coils), was considered a predictor variable of neonatal complications. Thus, the chance of neonatal complications reduced due to the increased length (odds ratio $=0.958$; CI 95\% $=0.93$ $0.98)$.

Moreover, in the multi-analysis of UCI effects on neonatal complications through controlling the underlying diseases and maternal age, as well as the interfering variables, the coil length was found to be a predictor of neonatal complications in the adjusted model (odds ratio $=0.958$ ). In addition to the coil length, variables such as maternal age $(P<0.0001)$ and the number of births $(P<0.0001)$ were identified as predictors of neonatal complications.

\section{Discussion}

Problems and abnormalities of the umbilical cord play a vital role in mortality and perinatal complications since the umbilical cord is an essential bridge between the fetus survival and occurrence of any complications during pregnancy. Additionally, in the case of chronicity or acuteness, the umbilical cord can either cause IUGR or

Table 2. Examining the Relationship Between the Umbilical Coil Index and the Studied Variables

\begin{tabular}{|c|c|c|c|c|c|}
\hline & & \multicolumn{3}{|c|}{ Coiling } & \multirow[b]{2}{*}{$P$ value } \\
\hline & & $\begin{array}{c}\text { Hyporcoil } \\
\text { No. (\%) }\end{array}$ & $\begin{array}{c}\text { Normocoil } \\
\text { No. (\%) }\end{array}$ & $\begin{array}{c}\text { Hypercoil } \\
\text { No. (\%) }\end{array}$ & \\
\hline \multicolumn{2}{|l|}{ Maternal age } & $28.10(6.8)$ & $26.52(6.19)$ & $27.78(6.93)$ & 0.199 \\
\hline \multirow{4}{*}{ Parity } & 1 & $26(66.7)$ & $196(61.8)$ & $29(70.7)$ & \multirow{4}{*}{$0.265^{a}$} \\
\hline & 2 & $10(25.6)$ & $87(27.4)$ & $8(19.8)$ & \\
\hline & 3 & $2(5.1)$ & $28(8.8)$ & $1(2.4)$ & \\
\hline & $\geq 4$ & $1(2.6)$ & $6(1.9)$ & $3(7.3)$ & \\
\hline \multirow{4}{*}{$\begin{array}{l}\text { Gestational } \\
\text { hypertension }\end{array}$} & No & $31(79.5)$ & $302(95.3)$ & $38(92.7)$ & \multirow{4}{*}{$0.004^{*}$} \\
\hline & Hypertension & $5(12.8)$ & $7(2.2)$ & $2(4.9)$ & \\
\hline & Preeclampsia & $2(5.1)$ & $8(2.5)$ & $1(2.4)$ & \\
\hline & Eclampsia & $1(2.6)$ & $0(0)$ & $0(0)$ & \\
\hline \multirow{3}{*}{ Diabetes } & No & $38(97.4)$ & 304 (59.9) & $38(92.7)$ & \multirow{3}{*}{$0.183^{*}$} \\
\hline & Diabetes & $1(2.6)$ & $3(0.9)$ & $2(4.9)$ & \\
\hline & Gestational diabetes & $0(0)$ & $10(3.2)$ & $1(2.4)$ & \\
\hline \multirow{3}{*}{ Amniotic fluid disorder } & No & $39(100)$ & $312(98.4)$ & $41(100)$ & \multirow{3}{*}{$0.999^{*}$} \\
\hline & Oligohydramnios & $0(0)$ & $3(0.9)$ & $0(0)$ & \\
\hline & Polyhydramnios & $0(0)$ & $2(0.6)$ & $0(0)$ & \\
\hline
\end{tabular}

${ }^{\mathrm{a}}$ Fisher exact test. 
Table 3. Examining the Umbilical Coil Index Based on Quantitative Variables

\begin{tabular}{|c|c|c|c|c|}
\hline & \multicolumn{3}{|c|}{ Coiling } & \multirow[b]{2}{*}{$P$ Value } \\
\hline & $\begin{array}{c}\text { Hyporcoil } \\
\text { No. (\%) }\end{array}$ & $\begin{array}{c}\text { Normocoil } \\
\text { No. (\%) }\end{array}$ & $\begin{array}{c}\text { Hypercoil } \\
\text { No. (\%) }\end{array}$ & \\
\hline Maternal age (y) & $28.10(6.8)$ & $26.52(6.19)$ & $27.78(6.93)$ & 0.199 \\
\hline Parity & $1.46 \pm 0.82$ & $1.51 \pm 0.75$ & $1.51 \pm 1.05$ & 0.933 \\
\hline Apgar $1 \mathrm{~min}$ & $8.74 \pm 0.75$ & $8.56 \pm 0.90$ & $8.59 \pm 1$ & 0.730 \\
\hline Apgar 5 min & $9.79 \pm 0.52$ & $9.71 \pm 0.78$ & $9.63 \pm 0.86$ & 0.646 \\
\hline Birth weight & $3.23 \pm 0.44$ & $3.12 \pm 0.58$ & $3.11 \pm 0.68$ & 0.541 \\
\hline
\end{tabular}

Table 4. Comparative Evaluation of Umbilical Coil Index, Umbilical Cord Length, and the Number of Coils Regarding Neonatal Complications

\begin{tabular}{|c|c|c|c|c|}
\hline & \multicolumn{3}{|c|}{ Coiling } & \multirow[b]{2}{*}{$P$ Value } \\
\hline & $\begin{array}{c}\text { Hyporcoil } \\
\text { No. (\%) }\end{array}$ & $\begin{array}{c}\text { Normocoil } \\
\text { No. (\%) }\end{array}$ & $\begin{array}{c}\text { Hypercoil } \\
\text { No. (\%) }\end{array}$ & \\
\hline Neonatal intensive care unit admission & $6(15.4)$ & $68(21.5)$ & $9(22)$ & $0.669^{\mathrm{a}}$ \\
\hline Intrauterine growth restriction & $1(2.6)$ & $13(4.1)$ & $2(4.9)$ & $0.894^{a}$ \\
\hline Meconium & $3(7.7)$ & $6(1.9)$ & $0(0)$ & $0.08^{b}$ \\
\hline
\end{tabular}

${ }^{\mathrm{a}}$ Chi-square. ${ }^{\mathrm{b}}$ Fisher exact test.

Table 5. Neonatal Complications of Both Groups

\begin{tabular}{|c|c|c|c|c|}
\hline & \multicolumn{3}{|c|}{ Coiling } & \multirow[b]{2}{*}{$P$ Value } \\
\hline & $\begin{array}{l}\text { Hyporcoil } \\
\text { No. (\%) }\end{array}$ & $\begin{array}{l}\text { Normocoil } \\
\text { No. (\%) }\end{array}$ & $\begin{array}{l}\text { Hypercoil } \\
\text { No. (\%) }\end{array}$ & \\
\hline Neonatal complication & $9(23.1)$ & $78(24.6)$ & $9(22)$ & $0.92^{\mathrm{a}}$ \\
\hline
\end{tabular}

${ }^{\mathrm{a}}$ Chi-square.

be followed by fetal death, respectively and thus affect the fetus life $(13,14)$.

Various studies indicate the UCI as an effective indicator in pregnancy outcomes. This study attempted to investigate the relationship between the UCI and neonatal complications. The UCI was obtained by dividing the number of coins by the cord length (in $\mathrm{cm}$ ) as 0.31 . Based on the results, the UCI had a significant association with BP in pregnancy and abnormal fetal HR. By controlling the effects of interferences, it was observed that the umbilical cord length, maternal age, and parity were among the predictive factors for the incidence of neonatal complications.

In addition, the average length of the umbilical cord, the number of coils and the mean of UCI in the studied samples were $51.6 \pm 12.0,16.02 \pm 4.48$, and $0.31 \pm 0.05$, respectively. Further, the normocoil index was obtained in the range of $0.23-0.37$. Based on this index, the coils included hypocoil ( $\mathrm{n}=39,9.8 \%)$, hypercoil $(\mathrm{n}=41$, $10.3 \%)$, and normocoil $(\mathrm{n}=317,79.85 \%)$. In several review studies, the mean values of the cord length and the number of coils were highly close, and the UCI varied from 0.23 to 0.23 , and their results were consistent with each other. However, the findings of these studies are somewhat different from the results of the current study. In all those studies, the majority of people (approximately $70 \%$ ) were within the normocoil scope, which is consistent with the finding of the present study. However, the UCIs varied in all these studies $(3,6,15-17)$, which do not match with the results of the current study.

In a study by Mittal et al(9), it was revealed that hypercoil (UCI higher than 0.30) was associated with intrauterine death and an inverse correlation was found between the UCI and the gestational age of intrauterine death. In most cases, it was related to intrauterine death in younger women with lower gestational age. Thus, the researcher recommended setting the UCI as part of a routine examination of the placenta in cases of intrauterine death.

The reviewed literature conducted by de Laat et al (11) indicated that the normal UCI was equal to $0.17 \pm 0.009$. In this study, the mean UCI and the number of cord coils were higher than those of the other studies. However, in terms of the coil situation, the result was in line with the findings of the other studies and the majority of people were in the normocoil group. However, the normocoil measure was different in various studies, which could be due to the differences in measuring the antenatal UCI and the UCI at birth. Furthermore, it may be due to the ultrasound errors in sampling from different parts of the cord which are resulted from the dynamicity of the UCI with the progress of gestational age and the accuracy of manual measurement in the number of coils after birth (18). The definition of abnormal coiling is not the same in the studies. The defined range for hypercoil and hypocoil is different. Moreover, the age of examining the UCI is different in numerous studies (11). 
Due to various reports on UCI, Ohno (19) pinpointed that coiling in umbilical vein and artery was not generally the same. Therefore, the UCI could not be sufficiently accurate for the assessment. Thus, he focused on the umbilical vein and suggested that the umbilical vein probably could have a direct and more effective impact on the physiology of placental- uterine blood flow compared to the umbilical artery.

Based on the findings of the present study it was found that hypertensive disorders in pregnancy (i.e., hypertension, preeclampsia, and eclampsia) have a statistical association with hypocoil and hypercoil situations. This is consistent with the results obtained by Chitra et al (15), Mustafa and Said (3), and Kashanian (6). Additionally, Ezimokhani et al (7) found a significant relationship between no coiled umbilical cord and preeclampsia, which indicated that cord coils enable the umbilical cord through creating elastic tonicity to resist against stretching, rotation, and pressure $(20,21)$ as much as possible and inhibit the effect of pressure on blood flow. This may justify the association between the hypocoil and preeclampsia.

The results of the current study indicated that women with a blood sugar disorder had mostly hypercoil umbilical cord in the current pregnancy. However, due to the small sample size, no significant difference was observed between diabetes and the UCI while in studies by Chitra et al (15) and Mustafa and Said (3), a significant relationship was reported between diabetes and hypercoil condition. However, Ezimonakhi et al (7) found a significant correlation between gestational diabetes and both types of coiling disorders. Similarly, Kashanian et al (6) demonstrated that the UCI was lower in the group with diabetes than in those without diabetes.

In addition, in a study evaluating the arterial cord ring index by ultrasound, a significant correlation of arterial cord ring index with preterm labor was detected, which, of course, was not observed in this study (22).

Further, based on the results, no relationship was found between the disorders of amniotic fluid volume and the UCI in the current study while in the study by Kashanian et al (6), oligohydramnios was significantly associated with hypercoiling. Furthermore, Mustafa and Said (3) reported a statistically significant correlation between oligohydramnios and hypercoiling, as well as polyhydramnios and hypercoiling. This relationship justifies the Edmondes assumption (23) as such by reducing UCI, the fluids reduce and the incidence of oligohydramnios increases.

Moreover, abnormal fetal $\mathrm{HR}$ had a significant relationship with abnormal UCI so that the abnormal fetal HR was higher in hypercoiling. However, the number of samples with abnormal fetal HR was very small while in both studies conducted by Chitra et al (15) and Mustafa and Said (3), the abnormal fetal HR had a meaningful relationship with both hypercoiling and hypocoiling conditions. Similarly, in Kashanian et al study (6), fetal distress was associated with hypercoiling. Therefore, in both types of coiling, these umbilical cords had less flexibility against rotation and pressure during the stress of labor. The results of the present and previous studies suggest that the abnormal UCI can be predictive of abnormal FHR, particularly the late loss. The best predictor level for UCI fetal distress was reported as 0.23 (16).

In the same vein, no relationship was observed between the low Apgar score in the first minute, maternal age, and number of births and the UCI while in Chitra's study (15), in women over 35 years, the LBW infants, and Apgar score below 6 , the incidence rates of hypercoiling and hypocoiling were higher than normocoiling. Additionally, Shobha and Sai Sharanya (8) reported a significant association between low Apgar score in the first minute and fetal distress with hypocoiling, IUGR with hypercoiling and the excretion of meconium with both groups; but it was not associated with maternal age. Similarly, Abdulrasul (17) indicated that the Apgar score below 6 at minute 5, fetal distress, and meconium excretion were associated with both hypocoiling and hypercoiling. The low birth weight (LBW) was also associated with hypocoiling.

In addition, Kashanian et al (6) demonstrated that the hypercoil subjects had a lower Apgar score. However, similar to the present study, no relationship was found between the age and the UCI. Nonetheless, there was a significant inverse correlation between the fetus weight and the UCI so that by increasing the UCI, the birth weight decreased. Further, weight more than $4000 \mathrm{~g}$ led to an increase in the hypercoiling. Furthermore, in the study conducted by Mustafa and Said (3), the age was associated with hypercoiling. This could be due to the fact that unlike other studies, only women who underwent vaginal birth, which has generally low risk, were included in the study.

Moreover, in the present study, no relationship was observed between any neonatal complications including the need to NICU, IUGR, and excretion of meconium with the UCI. However, in other studies such as those performed by Ezimokhai et al (7) and Chitra et al (15), a statistical correlation was found between IUGR and excretion of meconium and the UCI. Accordingly, it was claimed that there is a relationship between IUGR and hypercoiling which prevents the umbilical cord pressure due to the presence of sufficient coils along the umbilical cord. In hypocoils, it leads to reduced placental-fetus blood flow, and finally reduces the growth of the fetus over time. However, the excretion of meconium was associated with both types of UCI disorders. In the same vein, Mustafa and Said (3) reported that abnormal fetal HR (prolonged drop in late loss and tachycardia), the excretion of meconium, and LBW were correlated with both hypercoiling and hypocoiling types, but they were not related to the need for NICU.

Additionally, Chholak et al found that hypercoiled and IUGR had a significant relationship with hypochondrium, 
meconium excrement, apheresis below seven in the first and fifth minutes, and the need for admission to NICU (24).

Similarly, Shobha and Sai Sharanya (8) indicated that LBW was associated with hypercoiling. In cases which required NICU, the hypocoiling was significantly higher (Normocoil criterion: 0.06-0.4). This result is inconsistent with the findings of the present research and other studies. This could be due to the small sample size and type of subjects entered into the study based on the delivery type.

The relationship between pregnancy complications in two types of abnormal quilling was different in other studies so it is not possible to generalize the complications to any of the types, which may be due to differences in different determinations of UCI and cut off in the other studies.

In the current study, a multi-analysis was performed to assess the effects of UCI on the neonatal complications by controlling the interfering variants. Accordingly, it was found that in addition to the umbilical cord length, the maternal age and parity were among the predictors of neonatal complications as well.

\section{Conclusions}

Generally speaking, abnormal UCI was associated with undesirable results such as BP and abnormal HR. Therefore, the diagnosis of antenatal UCI can be of great help in recognizing the risky embryos and more quick treatment process. As a result, the placental examination is suggested to be routinely performed at postpartum as it is a simple and easy procedure which can be helpful in cases of fetal distress without any cause. In addition, the evaluation of UCI by ultrasonography can be beneficial in identifying fetuses at risk in the future.

\section{Conflict of Interests}

Authors declare that they have no conflict of interests.

\section{Ethical Issues}

This analytical cross-sectional study was approved by the Ethics Committee of Guilan University of Medical Sciences under the ethical code No. IR.GUMS.REC.1394.205 and implemented in Al-Zahra Hospital of Rasht from May 2015 to May 2016.

\section{Financial Support}

The present study was financially supported by the Vicechancellor Research Fellows of Guilan University of Medical Sciences.

\section{Acknowledgments}

This investigation was based on the thesis submitted to Guilan University of Medical Sciences by the fifth author, namely, Fatemeh Ebrahimi.

\section{References}

1. Ferguson VL, Dodson RB. Bioengineering aspects of the umbilical cord. Eur J Obstet Gynecol Reprod Biol. 2009;144 Suppl 1:S108-113. doi:10.1016/j.ejogrb.2009.02.024

2. de Laat MW, van Alderen ED, Franx A, Visser GH, Bots ML, Nikkels PG. The umbilical coiling index in complicated pregnancy. Eur J Obstet Gynecol Reprod Biol. 2007;130(1):66-72. doi:10.1016/j.ejogrb.2006.01.018

3. Mustafa SJ, Said AM. Association of umbilical coiling index in normal and complicated pregnancies. Diyala Journal of Medicine. 2013;5(1):15-22.

4. Benirschke K, Burton GJ, Baergen RN. Anatomy and Pathology of the Umbilical Cord. Pathology of the Human Placenta. Berlin, Heidelberg: Springer; 2012:309-375.

5. Jessop FA, Lees CC, Pathak S, Hook CE, Sebire NJ. Umbilical cord coiling: clinical outcomes in an unselected population and systematic review. Virchows Arch. 2014;464(1):105112. doi:10.1007/s00428-013-1513-2

6. Kashanian M, Akbarian A, Kouhpayehzadeh J. The umbilical coiling index and adverse perinatal outcome. Int J Gynaecol Obstet. 2006;95(1):8-13. doi:10.1016/j. ijgo.2006.05.029

7. Ezimokhai M, Rizk DE, Thomas L. Maternal risk factors for abnormal vascular coiling of the umbilical cord. Am J Perinatol. 2000;17(8):441-445. doi:10.1055/s-2000-13452

8. Shobha T, Sai Sharanya V. Umbilical coiling index as a marker of perinatal outcome. Int J Sci Res. 2016;5(4):19511955.

9. Mittal A, Nanda S, Sen J. Antenatal umbilical coiling index as a predictor of perinatal outcome. Arch Gynecol Obstet. 2015;291(4):763-768. doi:10.1007/s00404-014-3456-5

10. Sahoo K, Mahajan A, Shaha P, Kshirsagar NS. Evaluation of umbilical coiling index as a predictor of pregnancy outcome. Int J Health Sci Res. 2015;5(3):92-100.

11. de Laat MW, Franx A, van Alderen ED, Nikkels PG, Visser GH. The umbilical coiling index, a review of the literature. J Matern Fetal Neonatal Med. 2005;17(2):93-100. doi:10.1080/14767050400028899

12. Khong TY. Evidence-based pathology: umbilical cord coiling. Pathology. 2010;42(7):618-622. doi:10.3109/00313 025.2010.520309

13. Dutman AC, Nikkels PG. Umbilical hypercoiling in 2ndand 3rd-trimester intrauterine fetal death. Pediatr Dev Pathol. 2015;18(1):10-16. doi:10.2350/13-10-1390-oa.1

14. Pathak S, Hook E, Hackett G, et al. Cord coiling, umbilical cord insertion and placental shape in an unselected cohort delivering at term: relationship with common obstetric outcomes. Placenta. 2010;31(11):963-968. doi:10.1016/j. placenta.2010.08.004

15. Chitra T, Sushanth YS, Raghavan S. Umbilical coiling index as a marker of perinatal outcome: an analytical study. Obstet Gynecol Int. 2012;2012:213689. doi:10.1155/2012/213689

16. Rabiee $M$, Rafatie $S$, Naghizadeh MM. The association Between Umbilical Coiling Index and Fetal Distress. J Basic Clin Pathophysiol. 2016;4(2):1-4. doi:10.22070/ jbcp.2016.365

17. Abdulrasul EA. Umbilical coiling index as a predictor of adverse perinatal outcome. Int J Adv Res. 2014;2(2):101107.

18. Predanic M, Perni SC, Chasen ST, Baergen RN, Chervenak 
FA. Ultrasound evaluation of abnormal umbilical cord coiling in second trimester of gestation in association with adverse pregnancy outcome. Am J Obstet Gynecol. 2005;193(2):387-394. doi:10.1016/j.ajog.2004.12.092

19. Ohno Y, Terauchi M, Tamakoshi K. Perinatal outcomes of abnormal umbilical coiling according to a modified umbilical coiling index. J Obstet Gynaecol Res. 2016;42(11):1457-1463. doi:10.1111/jog.13092

20. Gupta S, Faridi MMA, Krishnan J. Umbilical coiling index. J Obstet Gynaecol India. 2006;56(4):315-319.

21. Machin GA, Ackerman J, Gilbert-Barness E. Abnormal umbilical cord coiling is associated with adverse perinatal outcomes. Pediatr Dev Pathol. 2000;3(5):462-471. doi:10.1007/s100240010103

22. Ndolo JM, Vinayak S, Silaba MO, Stones W. Antenatal Umbilical Coiling Index and Newborn Outcomes: Cohort Study. J Clin Imaging Sci. 2017;7:21. doi:10.4103/jcis. JCIS_111_16

23. Edmonds HW. The spiral twist of the normal umbilical cord in twins and in singletons. Am J Obstet Gynecol. 1954;67(1):102-120.

24. Chholak D, Gupta P, Khajotia S. Study to evaluate association of umbilical coiling index and perinatal outcome. Int J Reprod Contracept Obstet Gynecol. 2017;6(2):408-412. doi:10.18203/2320-1770.ijrcog20170025

(c) 2019 The Author (s); This is an open-access article distributed under the terms of the Creative Commons Attribution License (http://creativecommons.org/licenses/by/4.0), which permits unrestricted use, distribution, and reproduction in any medium, provided the original work is properly cited. 